\title{
Health Professionals' Counseling about Electronic Cigarettes for Smokers and Vapers in a Country That Bans the Sales and Marketing of Electronic Cigarettes
}

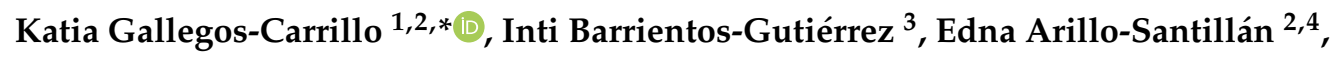 \\ Luis Zavala-Arciniega ${ }^{5}$, Yoo Jin Cho ${ }^{6}$ and James F. Thrasher ${ }^{2,6, *}$ \\ 1 Epidemiology and Health Services Research Unit, Mexican Institute of Social Security, Cuernavaca, \\ Morelos 62000, Mexico \\ 2 Tobacco Research Department, National Institute of Public Health, Cuernavaca, Morelos 62100, Mexico; \\ edna@insp.mx \\ 3 Evaluation and Surveys Research Center, National Institute of Public Health, Cuernavaca, Morelos 62100, \\ Mexico; inti.barrientos@insp.mx \\ 4 School of Demography, The Australian National University, Canberra, Australia/Tobacco Research \\ Department, National Institute of Public Health, Cuernavaca, Morelos 62100, Mexico \\ 5 Department of Epidemiology, University of Michigan, Ann Arbor, MI 48109, USA; \\ luiszavala171409@gmail.com \\ 6 Department of Health Promotion, Education \& Behavior, Arnold School of Public Health, University of \\ South Carolina, Columbia, SC 29208, USA; ycho@email.sc.edu \\ * Correspondence: katiagal@usc.edu (K.G.-C.); THRASHER@mailbox.sc.edu (J.F.T.); \\ Tel.: +52-777-100-1364 (K.G.-C.); +1-803-777-4862 (J.F.T.)
}

Received: 29 November 2019; Accepted: 8 January 2020; Published: 9 January 2020

\begin{abstract}
This study describes the prevalence and correlates of adult smokers' discussions about electronic cigarettes (e-cigarettes) with health professionals (HPs), including whether these discussions may lead smokers and vapers to use e-cigarettes for smoking cessation. Methods: We analyzed data from an online survey of Mexican smokers recruited from a consumer panel for marketing research. Participants who had visited an HP in the prior four months $(n=1073)$ were asked about discussions of e-cigarettes during that visit and whether this led them to try to quit. Logistic models regressed these variables on socio-demographics and tobacco use-related variables. Results: Smokers who also used e-cigarettes (i.e., dual users) were more likely than exclusive smokers to have discussed e-cigarettes with their HP (adjusted odds ratio $(\mathrm{AOR})=3.96$; $95 \%$ C.I. 2.73, 5.74), as were those who had recently attempted to quit smoking (AOR $=1.89 ; 95 \%$ C.I. 1.33, 2.7). Of smokers who had discussed e-cigarettes, $53.3 \%$ reported that the discussion led them to use e-cigarettes in their quit attempt. Also, dual users (AOR $=2.6 ; 95 \%$ C.I. $1.5,4.5)$ and daily smokers ( $>5$ cigarettes per day) $(\mathrm{AOR}=3.62 ; 95 \%$ C.I. $1.9,6.8)$ were more likely to report being led by their HP to use e-cigarettes in the quit attempt compared to exclusive smokers and non-daily smokers, respectively. Conclusions: Discussions between HP and smokers about e-cigarettes were relatively common in Mexico, where e-cigarettes are banned. These discussions appear driven by the use of e-cigarettes, as well as by greater smoking frequency and intentions to quit smoking.
\end{abstract}

Keywords: e-cigarettes; smoking cessation; public health; primary health care 


\section{Introduction}

The long-term health consequences of using electronic cigarettes (e-cigarettes), as well as their utility for smoking cessation [1-4], are uncertain. These uncertainties have made physician guidelines around e-cigarettes challenging, even though e-cigarettes are the most popular method smokers choose for quitting in high-income countries [5-7]. Studies in high-income countries have found that discussions about e-cigarettes between health professionals (HPs) and smokers are uncommon [8], regardless of the e-cigarette's regulatory framework in those countries $[9,10]$. Furthermore, studies from the smoker's point of view are scarce, refs. [8-11] with no known studies on this topic in low- and middle-income countries (LMICs) in spite of the increasing use of e-cigarettes in LMICs, including in LMICs that ban them, likely due to their relatively large informal economies [12,13]. Furthermore, as countries increasingly restrict and even ban e-cigarettes [13], there is a need to understand the frequency, content, and consequences of HPs discussions about e-cigarettes with their patients who smoke, in a country like Mexico where e-cigarettes are banned but yet widely accessible.

Previous cross-sectional studies in high-income countries have found that current and higher frequency use of e-cigarettes are associated with discussing e-cigarettes and receiving counseling from an HP to use them to quit smoking [9,10]. E-cigarette discussions were also more prevalent among smokers who were male [9], younger, and with higher educational attainment [10]. Furthermore, in a nationally representative survey in the United States, discussions about e-cigarettes with their HP (i.e., physicians and dentists), were less likely among ex-users of e-cigarettes than among current e-cigarettes users, whether they exclusively used e-cigarettes or also smoked cigarettes [8]. Additionally, making quit attempts were associated with having talked with an HP about e-cigarettes [9], although the temporality and direction of association were not clear.

Patient interest in having discussions about e-cigarettes with their HP appears high. One study reported that $24 \%$ of adult patients attending a family medicine clinic would want to have these discussions with their HPs; among recent e-cigarettes users, this proportion was double (62\%) [14]. To our knowledge, there are no studies from LMICs on HP discussions about e-cigarettes with their patients.

Mexico is a middle-income country where the importation, distribution, marketing, and sales of e-cigarettes are banned, as in most other Latin American countries [15] and, increasingly, around the world [16]. Nevertheless, in 2016, 12\% of middle schoolers had vaped in the past 30 days [17] and $18 \%$ of Mexican adult smokers had tried e-cigarettes [18]. A longitudinal study concluded that Mexican smokers who used e-cigarettes were no more likely than exclusive smokers to quit smoking or reduce cigarette consumption [19], which is consistent with some studies in other countries where device type and relatively frequent e-cigarettes use were not considered [20,21]. Furthermore, in 2009, only $17 \%-19 \%$ of Mexican smokers who had visited an HP in the last year received smoking cessation counseling from their HP, which is much lower than other Latin American countries like Brazil (57\%) or Argentina (60\%) [22,23].

How HPs in Mexico or other LMICs approach e-cigarettes are not known. As e-cigarettes use rapidly increases worldwide, it is necessary to examine HP counseling practices that integrate Nicotine Vaping Products (NVP) information, whether for discouraging or for promoting e-cigarettes use for smoking cessation and harm reduction or for discouraging their use. In the end, HP discussions and their effects may be critical to advancing public health goals to reduce the toll of tobacco product use, particularly as the science and optimal regulations for e-cigarettes and other novel nicotine products evolve. Our study aims to describe the prevalence and correlates of adult smokers' discussions about e-cigarettes with their HPs in Mexico, including whether these discussions may lead smokers to use e-cigarettes for smoking cessation. 


\section{Materials and Methods}

\subsection{Design and Study Population}

This study included Mexican adult smokers aged 18 or higher and who smoked in the last 30 days. In each of three separate survey waves (24 November-10 December 2018; 16 March-8 April 2019; 17 July-9 August 2019), 1500 participants were recruited through an online commercial panel for marketing research, using quotas for education (i.e., at least 500 with high school or lower attainment) and current e-cigarette use (at least 500) at each survey wave. While some participants were followed from one wave to the next, the present study includes data only from the first survey to which participants responded (wave 1, $n=1501$; wave 2, $n=1035$; wave 3, $n=799$ ), limiting the analytic sample to those who indicated that they had consulted with an HP in the 4 months prior to the survey $(n=1073)$, which represents the number of participants in this study. Surveys took between 20 and 25 minutes to complete, on average, and all study procedures were approved by the Institutional Review Board and Ethics Committee of the National Institute of Public Health of Mexico. Participants reported socio-demographic information, as well as smoking- and NVP-related perceptions and behaviors.

\subsection{Measures}

\subsubsection{Outcome Variables}

\section{Health Professional Consultation}

Participants were asked questions adapted from prior research on HP discussions about e-cigarettes [10], in which participants were first asked if, during the prior 4 months (the period between surveys), they had a medical consultation with an HP, including a general practitioner, nurse or other health professionals (yes vs. no). Those who reported doing so were asked: "On any visit to a doctor or health professional in the last 4 months, did a health professional talk to you about e-cigarettes?" (yes; no; don't know). Those who responded "yes" were asked: 1. "The last time you discussed e-cigarettes with a doctor or health professional, did you bring it up or did they?"(the doctor or health professional brought it up $=1$; I brought it up $=0$; don't know $=0$ ); and 2. "What advice did the doctor or health professional give you about e-cigarettes?" (they specifically recommended that I use e-cigarettes $=1$; they advised me against using e-cigarettes $=0$; they didn't express a view for or against e-cigarette use $=0$ ). Finally, participants were asked, "Did the conversation with your doctor or health professional lead you to make a quit attempt?" (Yes, and I used an e-cigarette in that quit attempt $=1$; Yes, but I didn't use the electronic cigarette in that attempt $=0$; the discussion did not persuade me to try to quit smoking $=0$ ).

\subsubsection{Independent Variables}

\section{Smoking- and E-Cigarettes-Related Variables}

Participant responses to questions on combustible cigarette use in the last 30 days were used to determine the frequency of use: (a) non-daily smoker; (b) daily smoker, $\leq 5$ cigarettes per day; and (c) daily smoker, $>5$ cigarettes per day. Among daily smokers, five cigarettes per day is the median cut point in prior research with Mexican smokers [24], including in representative samples [25], as in the sample for this study. Those who indicated that they had used e-cigarettes in the last 30 days were classified as dual users. Other smoking-related variables included having attempted to quit smoking in the prior 4 months (yes vs. no) and intentions to quit smoking within the next six months (yes vs. no). In addition, participants were asked if during a medical consultation in the last 4 months, an HP had counseled them to quit smoking (yes vs. no). 
Demographics Variables

Participants reported their sex (male or female), age (i.e., 18-29, 30-39, 40-49, or 50+ years), highest educational attainment (less than high school, high school graduate or technical studies or some college, college degree or postgraduate studies), and monthly household income in Mexican pesos (i.e., $<\$ 8000 ; \$ 8001-\$ 15,000 ; \$ 15,001-\$ 20,000 ;>\$ 20,000)$, where the exchange rate was approximately $\$ 20$ pesos to $\$ 1$ US dollar.

\subsection{Statistical Analyses}

Descriptive analyses were conducted to determine the frequency of electronic cigarette discussion according to socio-demographic and tobacco use variables.

Bivariate and multivariate logistic regression models were estimated to determine the socio-demographic and smoking-related correlates of discussing e-cigarette use among smokers who reported an HP consultation. Furthermore, in the group who discussed e-cigarettes, logistic regression models estimated the socio-demographic and tobacco-use related correlates of the HP bringing up the topic, the HP recommending e-cigarettes use, and if discussions with the HP led them to use e-cigarettes to quit smoking. All statistical models were adjusted by socio-demographic (sex, age, educational attainment, and monthly household income) and smoking- and e-cigarette-related variables (frequency of use, any quit attempts in the prior 4 months, and intentions to quit smoking within the next six months). Analyses were conducted using STATA 15.1 (StataCorp 2017, College Station, TX, USA).

\section{Results}

Of survey participants who were eligible for the study, all who had consulted an HP in the prior 4 months comprised the analytic sample $(n=1073$; see Table 1$)$. The mean age of respondents was 36.6 years, about half (52.4\%) were male, and almost $40 \%$ had high school education or lower. Of those who consulted an HP in the prior 4 months, $41 \%$ were dual users, and $49.2 \%$ had attempted to quit attempt during that same period of time.

Table 1. Sample characteristics of smokers and vapers having health professional (HP) consultations during the prior 4 months, aged 18 to 71, and living in Mexico 2018-2019.

\begin{tabular}{cc}
\hline Variables & $n=\mathbf{1 0 7 3}$ \\
\cline { 2 - 2 } & $\mathbf{( \% )}$ \\
\hline Age group & \\
$18-29$ & 33.2 \\
$30-39$ & 31.4 \\
$40-49$ & 16.3 \\
$50+$ & 16.3 \\
\hline Sex & \\
Female & 52.4 \\
Male & 47.6 \\
\hline Education & \\
Less than high school & 7.2 \\
High School graduate & 33.2 \\
Some college & 19.8 \\
College degree or higher & 39.9 \\
\hline
\end{tabular}


Table 1. Cont.

\begin{tabular}{cc}
\hline Variables & $\boldsymbol{n}=\mathbf{1 0 7 3}$ \\
\cline { 2 - 2 } & $\mathbf{( \% )}$ \\
\hline Household income & \\
$\leq 8000$ & 21.8 \\
$8000-15,000$ & 28.2 \\
$15,000-20,000$ & 17.4 \\
$>20,000$ & 28.3 \\
Missing & 4.2 \\
\hline Type of user & \\
Exclusive Cigarette user & 59 \\
Dual user & 41 \\
\hline Smoking frequency and intensity & 53.8 \\
Non-daily & 20.5 \\
Daily $\leq 5$ cigs & 25.7 \\
Daily $>5$ cigs & 50.8 \\
\hline No & 49.2 \\
\hline Yes & 56.9 \\
\hline Plan to quit & 43.1 \\
\hline During the next month/1-6 months
\end{tabular}

\subsection{HP Discussions about E-Cigarettes}

Among smokers and vapers who had an HP consultation during the last 4 months, 33.7\% $(n=362)$ discussed e-cigarettes with their HP (See Table 2). Dual users were significantly more likely to discuss with their HP about e-cigarettes (adjusted odds ratio (AOR) $=5.1 ; 95 \%$ C.I. 3.7, 7.2) than exclusive combustible cigarette smokers (see Table 2). Respondents who had an attempt to quit smoking in the last 4 months were also more likely to discuss e-cigarettes (AOR $=1.9 ; 95 \%$ C.I. 1.4, 2.7). In addition, those who reported their HP counseling them to quit smoking during the consultation were more likely to discuss e-cigarettes ( $\mathrm{AOR}=3.34 ; 95 \%$ C.I. 2.4, 4.6); after controlling for demographic and smoking-related variables, $p$-values $<0.05$ were considered statistically significant.

Table 2. Characteristics associated with having a discussion with their HP about electronic cigarettes among adult smokers aged 18 to 71, living in Mexico 2018-2019, $(n=1073)$.

\begin{tabular}{|c|c|c|c|c|c|}
\hline \multirow[b]{2}{*}{ Variables } & \multicolumn{5}{|c|}{ Discussion with Health Professionals about E-Cigarettes } \\
\hline & $\begin{array}{c}n(\%) \\
362(33.7)\end{array}$ & $\begin{array}{c}\text { Unadjusted Model } \\
\text { O.R. }\end{array}$ & CI 95\% & A.O.R. & CI 95\% \\
\hline \multicolumn{6}{|l|}{ Age } \\
\hline $18-29$ & $40 * *$ & Reference & & Reference & \\
\hline $30-39$ & 37 & 0.99 & $0.73,1.34$ & 1.02 & $0.69,1.5$ \\
\hline \multicolumn{6}{|l|}{ Sex } \\
\hline Female & $29 * *$ & Reference & & Reference & \\
\hline Male & 40 & 1.61 & $1.25,2.1^{* *}$ & 1.32 & $0.95,1.82$ \\
\hline \multicolumn{6}{|l|}{ Education } \\
\hline
\end{tabular}


Table 2. Cont.

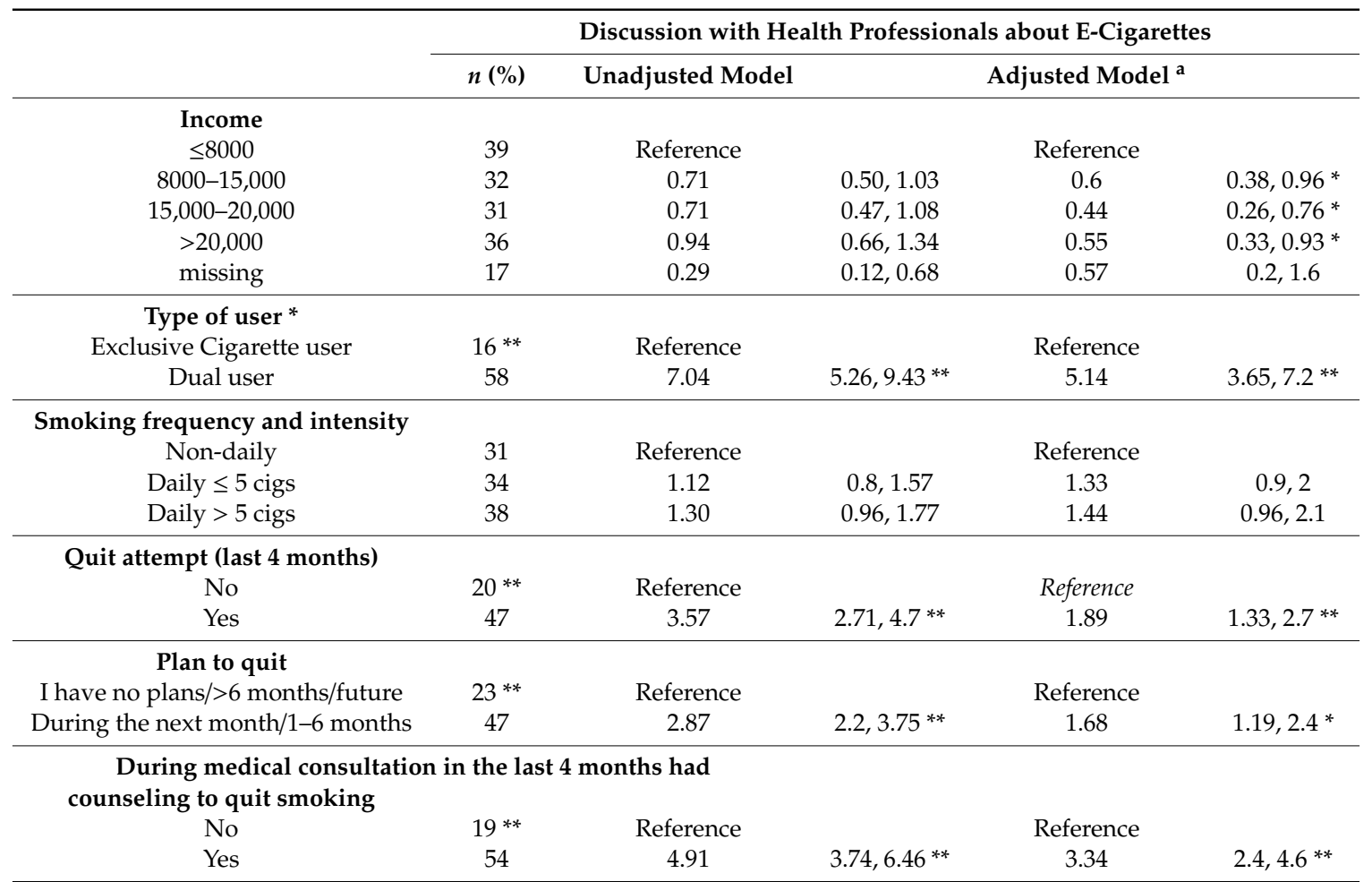

\footnotetext{
${ }^{*} p<0.05,{ }^{* *} p<0.01$. O.R. Odds Ratio, A.O.R. Adjusted Odds Ratio; ${ }^{a}$ Adjusted model included all variables specified in the table (147 missing data in family income variable).
}

\subsection{Content of E-Cigarettes Discussions with an HP and Advice about Smoking Cessation}

Among those who discussed e-cigarettes with their HP $(n=362), 46 \%$ reported that the HP brought up the topic. In adjusted models, the only statistically significant correlate was being a dual user $(\mathrm{AOR}=1.74 ; 95 \%$ C.I. $1.05,2.9$; see Table 3).

Table 3. Characteristics associated with the physician bringing up electronic cigarettes with adult smokers aged 18 to 71, living in Mexico 2018-2019 $(n=366)$.

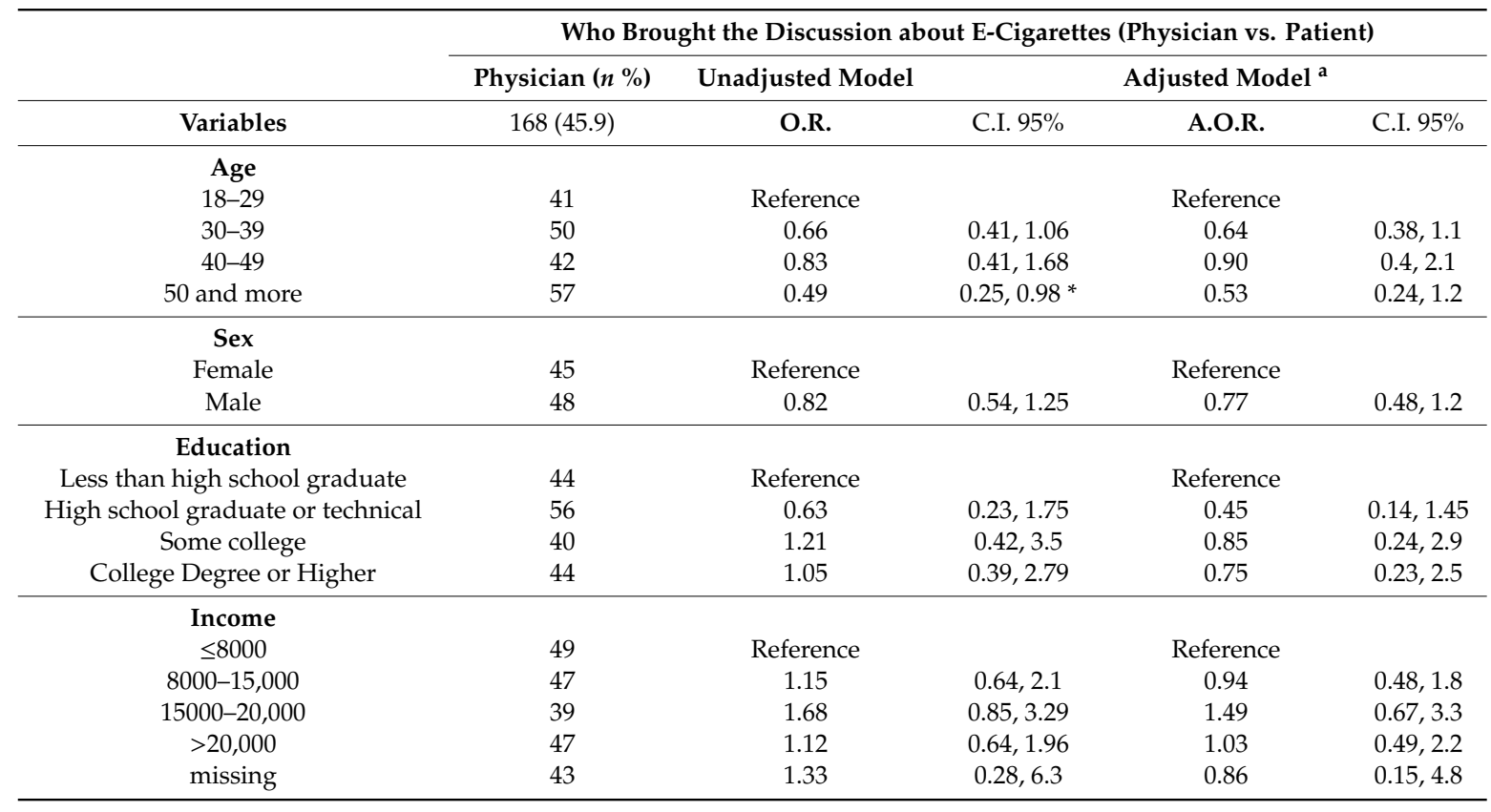


Table 3. Cont.

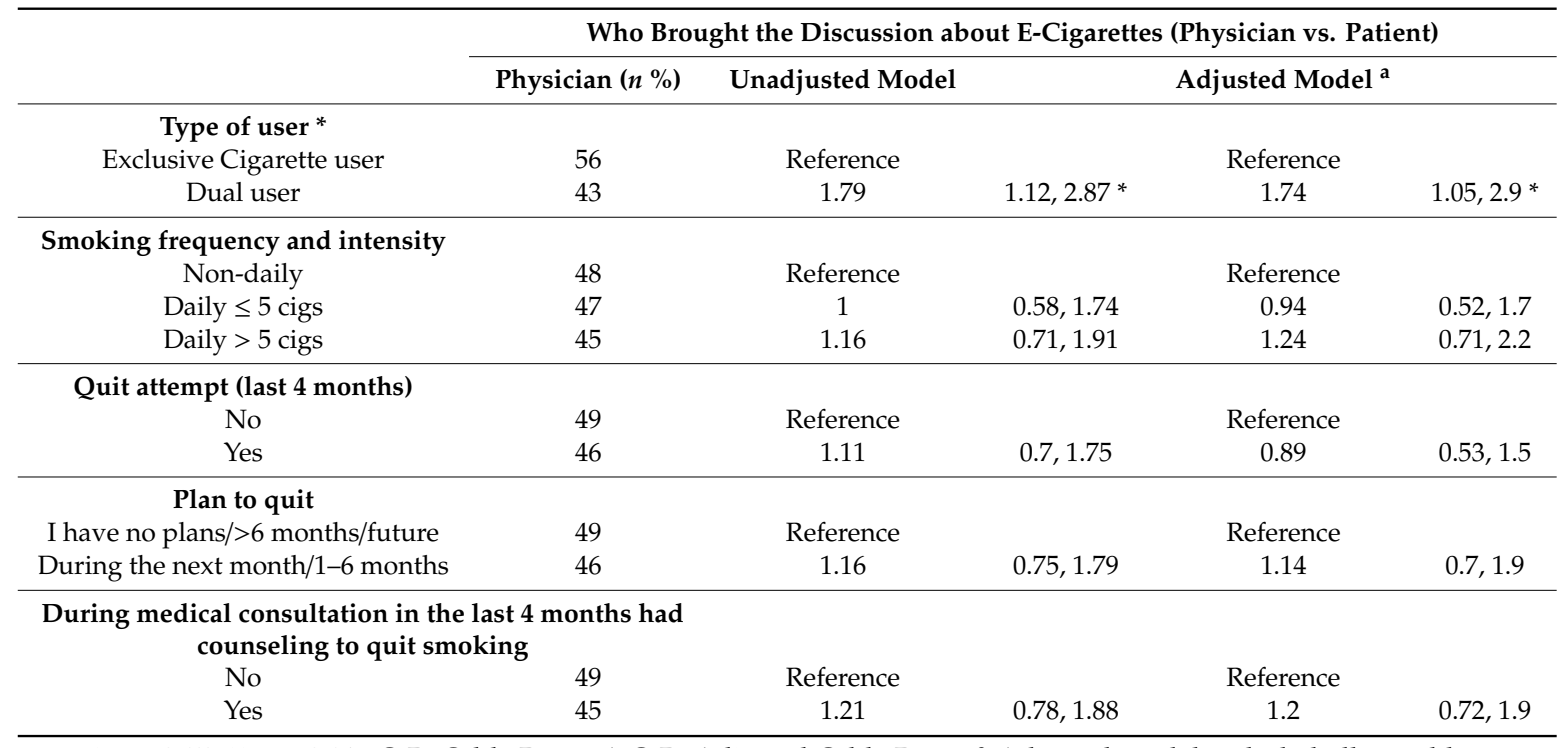

${ }^{*} p<0.05,{ }^{* *} p<0.01$. O.R. Odds Ratio, A.O.R. Adjusted Odds Ratio; ${ }^{\text {a }}$ Adjusted model included all variables specified in the table (147 missing data in family income variable).

Almost half (46\%) of smokers who discussed e-cigarettes indicated that their HP recommended their use, 23.5\% reported being advised against their use and 29.6\% indicated their HP did not express an opinion either for or against e-cigarettes use (Table 4). Furthermore, smokers who reported that their HP had counseled them to quit smoking were more likely to report that their HP recommended them to use e-cigarettes (AOR 1.7; 95\% C.I. 1.0, 2.7).

Table 4. Factors associated with physicians recommending e-cigarettes to adult smokers (among those who discussed e-cigarettes) aged 18 to 71, living in Mexico 2018-2019, $(n=375)$.

\begin{tabular}{|c|c|c|c|c|c|}
\hline \multirow[b]{3}{*}{ Variables } & \multicolumn{5}{|c|}{ Health Professional Recommendation: They Specifically Recommended Use E-Cigarettes } \\
\hline & \multirow{2}{*}{$\begin{array}{c}n \mathbf{n}(\mathbf{\%}) \\
n=171(46 \%)\end{array}$} & \multirow{2}{*}{$\begin{array}{c}\text { Unadjusted Model } \\
\text { O.R. }\end{array}$} & \multicolumn{3}{|c|}{ Adjusted Model $^{\text {a }}$} \\
\hline & & & C.I. $95 \%$ & A.O.R. & CI 95\% \\
\hline \multicolumn{6}{|l|}{ Age } \\
\hline $18-29$ & 42 & Reference & & Reference & \\
\hline $30-39$ & 54 & 1.57 & $0.98,2.51$ & 1.6 & $0.94,2.7$ \\
\hline 40-49 & 44 & 1.1 & $0.55,2.2$ & 1.05 & $0.5,2.3$ \\
\hline 50 and more & 39 & 0.85 & $0.44,1.66$ & 0.8 & $0.4,1.7$ \\
\hline \multicolumn{6}{|l|}{ Sex } \\
\hline Female & 43 & Reference & & Reference & \\
\hline Male & 49 & 1.23 & $0.82,1.85$ & 1.11 & $1.1,0.69,1.7$ \\
\hline \multicolumn{6}{|l|}{ Education } \\
\hline Less than high school graduate & 50 & Reference & & Reference & \\
\hline High school graduate or technical & 45 & 0.83 & $0.3,2.28$ & 0.74 & $0.23,2.4$ \\
\hline Some college & 50 & 1.00 & $0.35,2.84$ & 0.84 & $0.24,2.9$ \\
\hline College Degree or Higher & 45 & 0.77 & $0.29,2.04$ & 0.61 & $0.18,2.01$ \\
\hline \multicolumn{6}{|l|}{ Income } \\
\hline$\leq 8000$ & 38 & Reference & & Reference & \\
\hline $8000-15,000$ & 57 & 2.11 & $1.18,3.8 *$ & 2.62 & $1.3,5.1 *$ \\
\hline $15,000-20,000$ & 50 & 1.78 & $0.91,3.47$ & 2.14 & $0.97,4.7$ \\
\hline$>20,000$ & 47 & 1.25 & $0.71,2.2$ & 1.57 & $0.74,3.3$ \\
\hline missing & 3 & 1.29 & $0.27,6.14$ & 1.83 & $0.32,10.2$ \\
\hline \multicolumn{6}{|l|}{ Type of user } \\
\hline Exclusive Cigarette user & 48 & Reference & & Reference & \\
\hline Dual user & 47 & 0.97 & $0.61,1.54$ & 0.91 & $0.55,1.5$ \\
\hline
\end{tabular}


Table 4. Cont.

\begin{tabular}{|c|c|c|c|c|c|}
\hline & \multicolumn{5}{|c|}{ Health Professional Recommendation: They Specifically Recommended Use E-Cigarettes } \\
\hline & $n(\%)$ & Unadjusted Model & & justed Mod & \\
\hline \multicolumn{6}{|c|}{ Smoking frequency and intensity } \\
\hline Non-daily & 44 & Reference & & Reference & \\
\hline Daily $\leq 5$ cigs & 45 & 1.06 & $0.6,1.85$ & 0.95 & $0.52,1.7$ \\
\hline Daily $>5$ cigs & 53 & 1.43 & $0.87,2.36$ & 1.3 & $0.75,2.2$ \\
\hline \multicolumn{6}{|l|}{ Quit attempt (last 4 months) } \\
\hline No & 44 & Reference & & Reference & \\
\hline Yes & 48 & 1.19 & $0.75,1.88$ & 1.06 & $0.63,1.8$ \\
\hline \multicolumn{6}{|l|}{ Plan to quit } \\
\hline I have no plans/> 6 months/future & 41 & Reference & & Reference & \\
\hline During the next month/1-6 months & 51 & 1.48 & $0.96,2.29$ & 1.5 & $0.93,2.5$ \\
\hline \multicolumn{6}{|c|}{$\begin{array}{l}\text { During medical consultation in the last } 4 \text { months had } \\
\text { counseling to quit smoking }\end{array}$} \\
\hline No & $38 *$ & Reference & & Reference & \\
\hline Yes & 50 & 1.65 & $1.05,2.59 *$ & 1.66 & $1.03,2.7^{*}$ \\
\hline
\end{tabular}

\subsection{Use of E-Cigarettes in Quit Attempts Following Health Professional Discussions}

Among respondents who talked about e-cigarettes with their health professional, 53.3\% reported that the discussion led them to use an e-cigarettes in a subsequent quit attempt, though $32.4 \%$ reported that the discussion persuaded them to have a quit attempt without using e-cigarettes in that attempt, while $14.3 \%$ indicated that their discussion carried out with the HP did not lead them to make a quit attempt. (Table 5). Dual users were more likely than exclusive smokers to be persuaded to use e-cigarettes in their quit attempt $(\mathrm{AOR}=2.6 ; 95 \%$ C.I. $1.5,4.5)$. Being a daily smoker relative to nondaily smoker was also significantly associated with using e-cigarettes in their quit attempt, with a weaker association for those who smoked less than 5 cigarettes per day ( $\mathrm{AOR}=1 ; 95 \%$ C.I. 1.0, 3.5) than for those who smoked 5 cigarettes per day or more (AOR $=3.6 ; 95 \%$ C.I. 1.9, 6.8). Additionally, respondents reporting that they plan to quit during the next six months (AOR $=1.7 ; 95 \%$ C.I. 1, 2.8) and whose HP advised them to quit smoking at all were more likely to be persuaded by their HP to use e-cigarettes in their quit attempt (AOR $=2.0 ; 95 \%$ C.I. 1.2, 3.4).

Table 5. Factors associated with adult smokers using e-cigarettes to quit smoking because of HP consultation, adults aged 18 to 71, living in Mexico 2018-2019, $(n=362)$.

\begin{tabular}{|c|c|c|c|c|c|}
\hline \multirow[b]{3}{*}{ Variables } & \multicolumn{5}{|c|}{ Health Professional Persuade You to Use E-Cigarettes to Quit Smoking a } \\
\hline & \multirow{2}{*}{$\begin{array}{c}n(\%) \\
n=193(53.3)\end{array}$} & \multirow{2}{*}{$\begin{array}{c}\text { Unadjusted Model } \\
\text { O.R. }\end{array}$} & \multicolumn{3}{|c|}{ Adjusted Model ${ }^{b}$} \\
\hline & & & C.I. $95 \%$ & A.O.R. & C.I. $95 \%$ \\
\hline \multicolumn{6}{|l|}{ Age } \\
\hline $18-29$ & 57 & Reference & & Reference & \\
\hline $30-39$ & 53 & 0.84 & $0.52,1.36$ & 0.76 & $0.43,1.34$ \\
\hline $40-49$ & 45 & 0.91 & $0.45,1.82$ & 0.84 & $0.25,2$ \\
\hline 50 and more & 40.9 & 0.52 & $0.26,1.03$ & 0.4 & $0.17,0.92 *$ \\
\hline \multicolumn{6}{|l|}{ Sex } \\
\hline Female & 57 & Reference & & Reference & \\
\hline Male & 50 & 0.75 & $0.49,1.14$ & 0.71 & $0.43,1.19$ \\
\hline \multicolumn{6}{|l|}{ Education } \\
\hline Less than high school graduate & 39 & Reference & & Reference & \\
\hline High school graduate or technical & 53 & 1.77 & $0.63,4.96$ & 1.45 & $0.41,5.1$ \\
\hline Some college & 66 & 2.99 & $1.01,8.8 *$ & 2.68 & $0.68,10.5$ \\
\hline College Degree or Higher & 51 & 1.62 & $0.6,4.4$ & 0.92 & $0.25,3.4$ \\
\hline
\end{tabular}


Table 5. Cont.

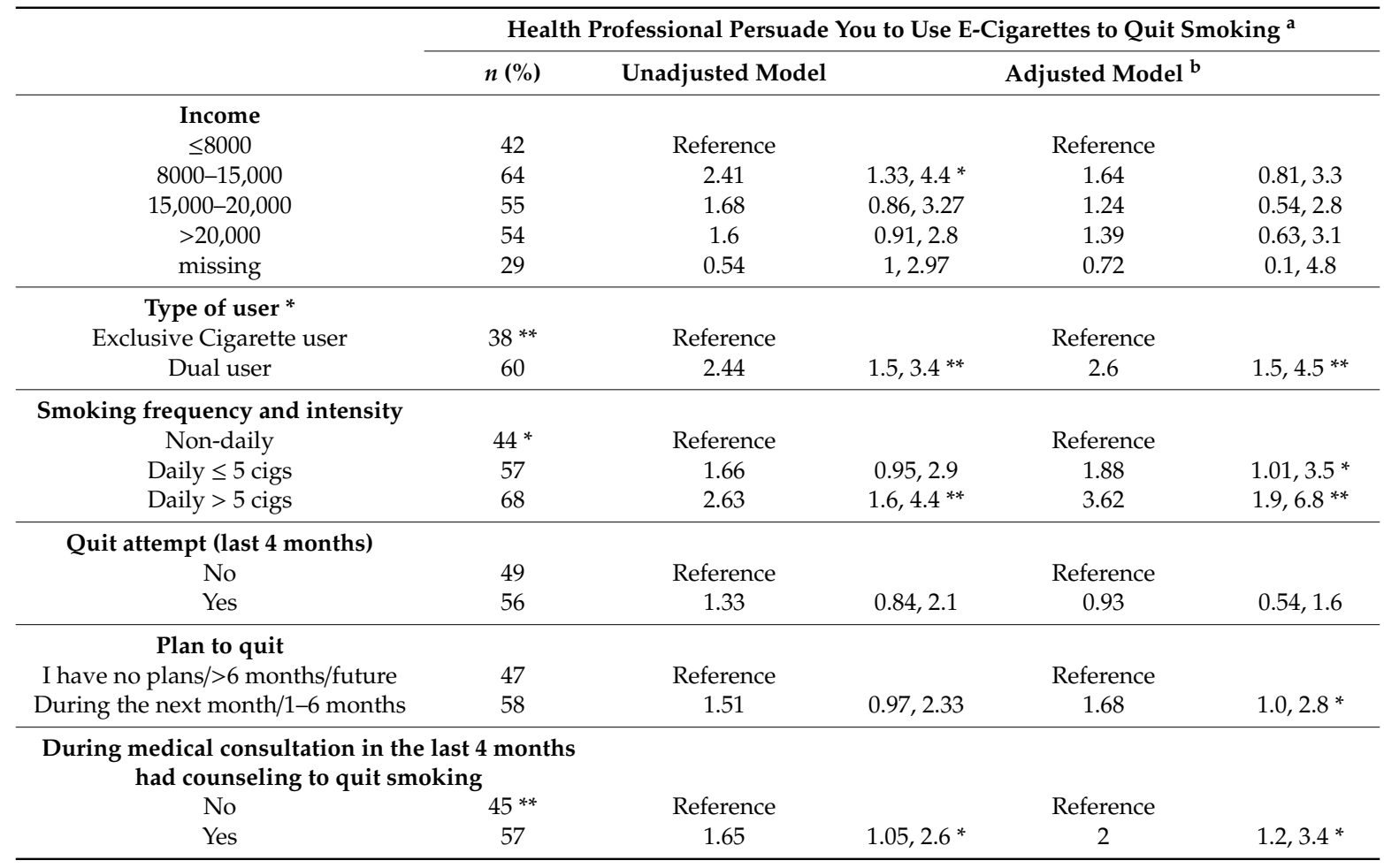

${ }^{*} p<0.05,{ }^{* *} p<0.01$. O.R. Odds Ratio, A.O.R. Adjusted Odds Ratio. ${ }^{\text {a }}$ Sample size includes only respondents who discussed e-cigarettes with their HP. ${ }^{b}$ Adjusted model included all variables specified in the table (147 missing data in family income variable). Reference: The discussion did not persuade me to try to quit smoking/Yes but I did not use the electronic cigarette in that attempt.

\section{Discussion}

Health professionals' counseling on smoking cessation is a fundamental component of tobacco control, with evidence from recent trials $[26,27]$ leading some agencies to recommend that all physicians discuss e-cigarettes with their patients who smoke [28], while others suggest the evidence is not sufficient for physician recommendations [29]. Nevertheless, our study suggests that a nontrivial percentage of HPs discussing e-cigarettes with their patients who smoke (34\%), even in Mexico, where e-cigarettes are banned. Studies in other countries have found a lower prevalence, ranging from $4 \%$ in Australia to $15 \%$ in studies in the U.S. $[8,9,12,30]$. The composition of our sample, which purposefully includes a higher percentage of e-cigarettes users, likely explains the higher prevalence we found. Furthermore, our relatively recent data collection effort may reflect the growing use of NVPs in Mexico.

Studies in the U.S. exploring this topic from the physician point of view indicated a higher frequency of these discussions among patients who smoke, the prevalence varies from $48 \%$ [31] to $65 \%$ [32], and 70\% [33], in studies carried out in the U.S. This gap in the perspectives of health professionals and patients about e-cigarettes discussions during health consultations indicates the importance of future research to clarify what accounts for these differences in perceptions.

Consistent with prior research [9], we found that being a dual user and having recently attempted to quit smoking were associated with NVP discussions. As with those other studies, the temporal sequence of HP consultation, e-cigarette use, and quit attempts are not clear. However, our analysis indicated that a significant percentage of smokers who discussed their e-cigarette use with their HP reported going on to try to quit with an e-cigarette. Nevertheless, they were still smoking at the time of the interview; hence, the quit attempt was not successful. Longitudinal research is sorely needed to help determine whether HPs can successfully promote quitting by encouraging e-cigarette use, including whether additional behavioral support is needed to achieve this goal, as suggested by recent clinical trials [24]. In the end, the greatest public health benefits would come from getting smokers who 
use e-cigarettes to quit e-cigarettes as well. However, previous studies in Mexico have found that only $3 \%$ of adult smokers who have tried to quit report that they received smoking cessation counseling from an HP [34]—a substantial amount of work remains to be done in this area [13,30,35-37].

It is noteworthy that participants reported that HPs initiated discussions about e-cigarettes, despite the fact that they are banned in Mexico. However, e-cigarettes are widely available, perhaps because of the size of the informal economy, which represents $56.9 \%$ of all jobs in Mexico [38]. Furthermore, e-cigarette purchase and consumption are not illegal. Hence, it is likely that most Mexicans do not know about the e-cigarette ban, including physicians. Future research should explore physician perspectives about opportunities to promote e-cigarettes for the cessation and harm reduction in the context of bans, especially given recent concerns about vaping-related illnesses and their apparent link to black-market products, particularly cannabis oils.

Limitations of this study include our use of a convenience sample recruited from a consumer marketing panel. As the sample came from an unknown sampling frame, the generalizability of results is not clear; however, the sample was purposefully recruited to represent key market segments in Mexico, even though it over-represented higher socioeconomic status groups. Furthermore, because of our desire to have statistical power for evaluating the impact of e-cigarette use, we oversampled smokers who also used e-cigarettes, which likely led to overestimates of e-cigarette discussions and their use in quit attempts. Furthermore, our study did not disentangle issues around the temporal ordering of events and potential recall bias related to counseling and content of HP discussions from the participants' points of view. However, our questions asked about a shorter time frame (i.e., the prior 4 months) than in other studies (e.g., last year [8,10]), which likely reduced recall bias. Finally, the few online survey questions we used to characterize the content of conversations with HPs may not capture key dynamics of the interaction (e.g., trust or competing clinical demands) that matter for the cessation of smoking. Future qualitative research on this topic should be considered to more comprehensively characterize and address the complexity and associated effects of these discussions.

\section{Conclusions}

Discussions and recommendations to use e-cigarettes by physicians appear prevalent in Mexico, particularly amongst smokers who also use e-cigarettes. When the discussion of electronic cigarettes (e-cigarettes) took place, almost half of HPs brought up the topic and recommended their use, while more than half of smokers reported going on to use electronic cigarettes (e-cigarettes) in a quit attempt. This suggests that HPs may have an important role to play in smoking cessation that involves e-cigarettes. Future studies are needed to assess smoking cessation outcomes that follow from the HP encounter, including clinical trials to determine best clinical practices for promoting smoking cessation, including e-cigarette use for harm reduction, as well as the cessation of all nicotine products.

Author Contributions: Conceptualization, K.G.-C. and J.F.T.; methodology, J.F.T. and I.B.-G.; software, L.Z.-A.; validation, I.B.-G. and L.Z.-A.; formal analysis, K.G.-C. and J.F.T.; investigation, I.B.-G. and E.A.-S.; resources, I.B.-G.; data curation, L.Z.-A.; writing-original draft preparation, K.G.-C. and J.F.T.; writing—review and editing, K.G.-C., I.B.-G., E.A.-S., Y.J.C. and J.F.T.; visualization, I.B.-G. and L.Z.-A.; supervision, J.F.T., I.B.-G. and E.A.-S.; project administration, I.B.-G.; funding acquisition, J.F.T., please turn to the CRediT taxonomy for the term explanation. Authorship must be limited to those who have contributed substantially to the work reported. All authors have read and agreed to the published version of the manuscript.

Funding: This research was funded by the Fogarty International Center of the National Institutes of Health under award number R01 TW010652. The content is solely the responsibility of the authors and does not necessarily represent the official views of the National Institutes of Health.

Conflicts of Interest: The authors declare no conflict of interest. 


\section{References}

1. National Academies of Sciences, Engineering, and Medicine. Public Health Consequences of E-Cigarettes; The National Academies Press: Washington, DC, USA, 2018; Available online: https://www.nap.edu/read/ 24952/chapter/1 (accessed on 15 October 2019).

2. Kalkhoran, S.; Glantz, S.A. E-cigarettes and smoking cessation in real-world and clinical settings: A systematic review and meta-analysis. Lancet Respir. Med. 2016, 4, 116-128. [CrossRef]

3. McNeill, A.; Brose, L.S.; Calder, R.; Bauld, L.; Robson, D. Evidence Review of E-Cigarettes and Heated Tobacco Products 2018; Public Health England: London, UK, 2018. Available online: https://assets.publishingservice.gov.uk/government/uploads/system/uploads/attachment_data/file/684963/ Evidence_review_of_ecigarettes_and_heated_tobacco_products_2018.pdf (accessed on 14 October 2019).

4. Green, S.H.; Bayer, R.; Fairchild, A.L. Evidence, policy, and e-cigarettes-will England reframe the debate? N. Engl. J. Med. 2016, 374, 1301-1303. [CrossRef] [PubMed]

5. American Medical Association. AMA Strengthens Policy on Electronic Cigarettes to Further Protect Youth. American Medical Association, 2015. Available online: http://www.ama-assn.org/ama/pub/news/news/2015/ 2015-06-09-ama-policy-protect-youth.page (accessed on 10 October 2019).

6. Bhatnagar, A.; Whitsel, L.P.; Ribisl, K.M. Electronic cigarettes: A policy statement from the American Heart Association. Circulation 2014, 130, 1418-1436. [CrossRef] [PubMed]

7. Tobacco Advisory Group of the Royal College of Physicians. Nicotine Without Smoke: Tobacco Harm Reduction; Royal College of Physicians: London, UK, 2016.

8. Drouin, O.; McMillen, R.C.; Klein, J.D.; Winickoff, J.P. E-Cigarette advice to patients from physicians and dentists in the United States. Am. J. Health Promot. 2018, 32, 1228-1233. [CrossRef]

9. Kollath-Cattano, C.; Thrasher, J.F.; Osman, A.; Andrews, J.O.; Strayer, S.M. Physician advice for e-cigarette use. J. Am. Board Fam. Med. 2016, 29, 741-747. [CrossRef]

10. Gravely, S.; Thrasher, J.F.; Cummings, K.M.; Ouimet, J.; McNeill, A.; Meng, G. Discussions between Health Professionals and Smokers about Nicotine Vaping Products: Results from the 2016 ITC Four Country Smoking and Vaping Survey. Addiction 2019, 114, 71-85. [CrossRef]

11. Berg, C.J.; Haardoerfer, R.; Escoffery, C.; Zheng, P.; Kegler, M. Cigarette Users' Interest in Using or Switching to Electronic Nicotine Delivery Systems for Smokeless Tobacco for Harm Reduction, Cessation, or Novelty: A Cross-Sectional Survey of US Adults. Nicotine Tob. Res. 2014, 17, 245-255. [CrossRef]

12. Gravely, S.; Fong, G.T.; Cummings, K.M. Awareness, trial, and current use of electronic cigarettes in 10 countries: Findings from the ITC project. Int. J. Environ. Res. Public Health 2014, 11, 11691-11704. [CrossRef]

13. Kennedy, R.D.; Awopegba, A.; De Leon, E.; Cohen, J.E. Global approaches to regulating electronic cigarettes. Tob. Control 2017, 26, 440-445. [CrossRef]

14. Doescher, M.P.; Wu, M.; Rainwater, E.; Khan, A.S.; Rhoades, D.A. Patient Perspectives on Discussions of Electronic Cigarettes in Primary Care. J. Am. Board Fam. Med. 2018, 31, 73-82. [CrossRef]

15. Ley General para el Control del Tabaco 2018. Artículo 16, Apartado VI. Diario Oficial de la Federación. 15 June 2018. Available online: http://www.diputados.gob.mx/LeyesBiblio/pdf/LGCT_150618.pdf (accessed on 16 August 2019).

16. Gulland, A. WHO urges restrictions on e-cigarettes. BMJ 2016, 355, i5991. [CrossRef]

17. Barrientos-Gutierrez, I.; Lozano, P.; Arillo-Santillan, E.; Morello, P.; Mejia, R.; Thrasher, J.F. Technophilia: A new risk factor for electronic cigarette use among early adolescents? Addict. Behav. 2019, 91, 193-200. [CrossRef] [PubMed]

18. Zavala-Arciniega, L.; Reynales-Shigematsu, L.M.; Lozano, P.; Rodríguez-An-drade, M.Á.; Arillo-Santillán, E.; Thrasher, J.F. Patterns of awareness and use of electronic cigarettes in Mexico, a middle-income country that bans them: Results from a 2016 national survey. Prev. Med. 2018, 116. [CrossRef] [PubMed]

19. Lozano, P.; Arillo-Santillán, E.; Barrientos-Gutiérrez, I.; Zavala-Arciniega, L.; Reynales-Shigematsu, L.M.; Thrasher, J.F. E-cigarette use and its association with smoking reduction and cessation intentions among Mexican smokers. Salud Publica Mex. 2019, 61, 276-285. [CrossRef] [PubMed]

20. Giovenco, D.P.; Delveno, C.D. Prevalence of population smoking cessation by electronic cigarette use status in a national sample of recent smokers. Addict. Behav. 2018, 76, 129-134. [CrossRef] 
21. Brose, L.S.; Hitchman, S.C.; Brown, J.; West, R.; McNeill, A. Is the use of electronic cigarettes while smoking associated with smoking cessation attempts, cessation and reduced cigarette consumption? A survey with a 1-year follow-up. Addiction 2015, 110. [CrossRef]

22. Center for Disease Control and Prevention (CDC). Health-care provider screening for tobacco smoking and advice to quit-17 countries, 2008-2011. MMWR Morb. Mortal. Wkly. Rep. 2013, 62, 920-927.

23. Owusu, D.; Wang, K.S.; Quinn, M.; Aibangbee, J.; John, R.M.; Mamudu, H.M. Health Care Provider Intervention and Utilization of Cessation Assistance in 12 Low- and Middle-Income Countries. Nicotine Tob. Res. 2019, 21, 188-196. [CrossRef]

24. Swayampakala, K.; Thrasher, J.F.; Hardin, J.W.; Titus, A.R.; Liu, J.; Fong, G.T.; Fleischer, N.L. Factors associated with changing cigarette consumption patterns among low-intensity smokers: Longitudinal findings across four waves (2008-2012) of ITC Mexico Survey. Addict. Behav. Rep. 2018, 8, 154-163. [CrossRef]

25. GATS. Encuesta Global de Tabaquismo en Adultos; Ministry of Health: Mexico City, Mexico, 2009.

26. Hajek, P.; Phillips-Water, A.; Przulj, D.; Pesola, F.; Myers Smith, K.; Bisal, N.; Li, J.; Parrott, S.; Sasieni, P.; Dawkins, L.; et al. A Randomized trial of E-Cigarettes versus Nicotine-Replacement Therapy. NEJM 2019, 380, 629-637. [CrossRef]

27. Hartmann-Boyce, J.; McRobbie, H.; Bullen, C.; Begh, R.; Stead, L.F.; Hajek, P. Electronic cigarettes for smoking cessation. Cochrane Database Syst. Rev. 2016, 9, CD010216. [CrossRef] [PubMed]

28. McNeill, A.; Brose, L.S.; Calder, R.; Bauld, L.; Robson, D. Vaping in England: An Evidence Update February 2019; Public Health England: London, UK, 2019.

29. McRobbie, H.; Bullen, C.; Hartmann-Boyce, J.; Hajek, P. Electronic cigarettes for smoking cessation and reduction. Cochrane Database Syst. Rev. 2014, 12, CD010216.

30. Brown-Johnson, C.G.; Burbank, A.; Daza, E.J.; Wassmann, A.; Chieng, A.; Rutledge, G.W. Online patient-provider e-cigarette consultations: Perceptions of safety and harm. Am. J. Prev. Med. 2016, 51, 882-889. [CrossRef] [PubMed]

31. Kandra, K.L.; Ranney, L.M.; Lee, J.G.L. Goldstein AO (2014) Physicians' Attitudes and Use of E-Cigarettes as Cessation Devices, North Carolina. PLoS ONE 2013, 9, e103462.

32. Steinberg, M.B.; Giovenco, D.P.; Delnevo, C.D. Patient-physician communication regarding electronic cigarettes. Prev. Med. Rep. 2015, 2, 96-98. [CrossRef]

33. Nickels, A.S.; Warner, D.O.; Jenkins, S.M.; Tillburt, J.; Hays, J.T. Beliefs, Practices and Self-efficacy of US Physicians Regarding Smoking Cessation and Electronic Cigarettes: A National Survey. Nicotine Tob. Res. 2017, 2, 197-207. [CrossRef]

34. Reynales-Shigematsu, L.M.; Zavala-Arciniega, L.; Paz-Ballesteros, W.C.; Gutiérrez-Torres, D.S.; García-Buendía, J.C.; Rodriguez-Andrade, M.A.; Gutiérrez-Reyes, J.; Franco-Núñez, A.; Romero-Martínez, M.Y.; Mendoza-Alvarado, L. Secretaría de Salud. Encuesta Nacional de Consumo de Drogas, Alcohol y Tabaco 2016-2017: Reporte de Tabaco; INPRFM: Ciudad de México, Mexico, 2017.

35. Fiore, M.C.; Schroeder, S.A.; Baker, T.B. Smoke, the chief killer-Strategies for targeting combustible tobacco use. N. Engl. J. Med. 2014, 370, 297-299. [CrossRef]

36. Borland, R.; Li, L.; Driezen, P.; Wilson, N.; Hammond, D.; Thompson, M.E. Cessation assistance reported by smokers in 15 countries participating in the International Tobacco Control (ITC) policy evaluation surveys. Addiction 2012, 107, 197-205. [CrossRef]

37. West, R.; Raw, M.; McNeill, A. Health-care interventions to promote and assist tobacco cessation: A review of efficacy, effectiveness and affordability for use in national guideline development. Addiction 2015, 110, 1388-1403. [CrossRef]

38. INEGI. Resultados de la Encuesta Nacional de Ocupación y Empleo (ENOE); INEGI: Aguascalientes, Mexico, 2019; Available online: https://www.inegi.org.mx/contenidos/saladeprensa/boletines/2019/enoe_ie/enoe_ie2019_05. pdf (accessed on 15 December 2019).

(C) 2020 by the authors. Licensee MDPI, Basel, Switzerland. This article is an open access article distributed under the terms and conditions of the Creative Commons Attribution (CC BY) license (http://creativecommons.org/licenses/by/4.0/). 